\title{
GENETIC CONTROL OF MULTIPLE MOLECULAR FORMS OF THE ACID PHOSPHOMONOESTERASES IN THE HOUSE FLY, MUSCA DOMESTICA
}

\author{
ZEN-ICHI OGITA AND TSUTOMU KASAI
}

Department of Genetics, Medical School, Osaka University, Osaka

Received February 5, 1965

In previous papers (Ogita 1962, Ogita and Kasai 1965 a) the multiple molecular forms of esterases were demonstrated in the tissue extract of the house fly on the basis of the ability of zymogram bands to hydrolyse naphthylacetate esters after they had been separated by thin-layer electrophoresis in agar-gel according to the method developed by Ogita (1962, $1963 \mathrm{a}, \mathrm{b}, 1964)$. These esterase bands, however, were not related to the insecticide-resistance. But the ability to hydrolyse methyl- $n$-butyrate esters by an ali-esterase enzyme was shown, by the pH-indicator method (Ogita and Kasai $1964 \mathrm{a}$, $1965 \mathrm{~b})$, to be less active in the diazinon-resistant than in the susceptible strains, as reported by van Asperen and Oppenoorth (1960). Their suggestion that a modified ali-esterase may be important in the detoxyfication of organophosphate insecticide by resistant strains of house flies, and the suggestion by Menzel et al. (1963) that resistance to organophosphate insecticide such as malathion is related to higher phosphatase activity, indicate the need for further study of the phosphatases of resistant and susceptible strains of insects.

Multiple molecular forms of phosphatases have been described in a large variety of organisms. Menzel et al. (1963) showed that the phosphatase activities on disodium $\beta$-naphthyl phosphate in the tissue extract of house flies at $\mathrm{pH} 6.8$ after starch-gel electrophoresis are more numerous and more active in the malathion-resistant than in the susceptibe strains. Beckman and Johnson (1964) found an electrophoretic variation in the larval alkaline phosphatase of Drosophila melanogaster, the inheritance of which was controlled by a pair of codominant alleles on the third chromosome.

Levinthal et al. (1962) reported that the alkaline phosphatase of $E$. coli showed four and possibly five distinct bands after electrophoresis in starch gel, and some mutants showed electrophoretic mobilities of all the bands different from those of the wild type. They suggested that the multiple bands are all products of the same gene. Human red-cell phosphatase was found to show differences in the electrophoretic mobilities and relative intensities of the components present, and five distinct phenotypes have been recognized (Hopkinson, Spencer and Harris 1963). It has been suggested that these differences may be explained by postulating the occurrence of three allelic 
genes, $P^{\mathfrak{a}}, P^{\mathrm{b}}$, and $P^{\mathrm{c}}$. Electrophoretic variations of phosphatases in sheep serum (Rendel and Stormont 1964) and in cattle serum (Gahne 1963) have also been reported. The existence of five fundamental types of acid phosphatase has been found in larval blood of the silkworm (Yoshitake and Akiyama 1964). These acid phosphatase isozymes are under the control of codominant allelic genes. Short communications on multiple forms of the acid phosphomonoesterase in the house fly were already reported (Ogita and Kasai 1963, 1964b).

In the present report, the changes in phosphomonoesterase patterns occurring at critical stages of development, and the experiments designed to determine the 5 th-chromosome locus responsible for acid phosphomonoesterases, are described, together with some discussion on the relationship between these acid phosphomonoesterase bands and resistance to organophosphate insecticides.

\section{MATERIALS AND METHODS}

\section{Insects}

The following insecticide-resistant and susceptible strains of the house fly, Musca domestica L., stocked at Osaka University were used: three diazinon resistant strains, (1) $203 d$, (2) P-9, (3) RP; one BHC resistant strain, (4) Hikone-R; one DDT resistant strain, (5) K-3926; two wild type susceptible strains, (6) NAIDM, (7) Takatsuki; and three susceptible and multichromosomal mutant strains, (8) ro; $c t ; c m ~(2 ; 4 ; 5=$ rough eyed; cut wings; carmine eyed), (9) bwb; ocra; ct; ar; ac (2;3;4; 5;6=brown body; ocra eyed; cut wings; abnormal antennae; wings curled up), (10) car ar ( $5=$ carnation eyed and abnormal antennae).

The origin and insecticide-susceptibility of these strains have been described in detail elsewhere (Ogita and Kasai 1965 a). All strains were reared on a larval medium containing equal portion of wheat bran, powdered Oriental Compressed Diet (Oriental Yeast Co. Ltd.) and fish meal, and the adults were fed on powdered milk and water.

\section{Quantitative enzyme assay}

Ether-anaesthetized flies were homogenized in deionized water with a glass homogenizer for 2 minutes. The crude brei was centrifuged at 10,000 r.p.m. (ca. 12,000 g) for 60 minutes and the supernatant was assayed for hydrolytic activity against disodium $\alpha$-naphthyl phosphate. Test solution was diluted to contain the equivalent of one whole fly per ml.

For the assay of supernatant extracts, Gomori's procedure (1950) was modified. One $\mathrm{ml}$ of $1 \times 10^{-3} \mathrm{M}$ disodium $\alpha$-naphthyl phosphate, $1 \mathrm{ml}$ of $0.2 \mathrm{M}$ tris or acetate buffer, and $2 \mathrm{ml}$ of deionized water (or $1 \mathrm{ml}$ of inhibitor solution and $1 \mathrm{ml}$ of water) were pipetted into test tubes and $1 \mathrm{ml}$ of supernatant extract was added. After 60 minutes incubation at $37^{\circ} \mathrm{C}$ the tubes were removed from the water bath and $2 \mathrm{ml}$ of $0.3 \mathrm{M}$ 
phosphate buffer, $\mathrm{pH} 6.8$, and $1 \mathrm{ml}$ of $0.4 \%$ naphthanil diazoblue B solution were pipetted, then the solution was shaken and allowed to stand at room temperature.

The colour reaction was stopped 15 minutes later with $1 \mathrm{ml}$ of $40 \%$ trichloroacetic acid, and the brownish-red product was extracted with $6 \mathrm{ml}$ ethyl acetate, and then the optical density was measured at $600 \mathrm{~m} \mu$ and corrected for non-enzymic hydrolysis.

\section{Electrophoretic procedures}

Ether-anaesthetized flies were homogenized in an equal weight of water, and the homogenate was centrifuged to remove debris at 10,000 r.p.m. (ca. $12,000 \times \mathrm{g}$ ) for 60 minutes, the supernatant being retained. To assay the various parts of the body for the localization of enzymes, the body fluid was absorbed on a strip of filter paper and applied directly to the agar-gel layer, or the heads and guts were collected and their extracts were used. For the enzyme assay accompanying the genetic analysis, individual flies were crushed with one drop of water on glass plate and the resultant brei was tested.

Electrophoretic procedures were carried out as described by Ogita (1962, $1963 \mathrm{a}, \mathrm{b}$, 1964). For the separation of acid phosphomonoesterases, the medium containing $0.7 \mathrm{~g}$ of agar and $0.7 \mathrm{~g}$ of polyvinylpyrrolidone (Luviskol-K-90 powder, molecular weight ca. $700,000)$ in $100 \mathrm{ml}$ of $\mathrm{pH} 6.8$ potassium phosphate buffer of ionic strength $0.01 \mu$ was employed.

The agar-gel layer of $0.7 \mathrm{~mm}$ thickness was prepared on a glass plate, $16.5 \times 15 \mathrm{~cm}$, to have a very smooth surface. After the samples had been applied on the agar-gel layer, electrophoresis was carried out at $0.75 \mathrm{~mA} / \mathrm{cm}$ for 90 minutes in a cold room at $5 \sim 10^{\circ} \mathrm{C}$. Then the substrate-diazonium solution consisting of $0.5 \%$ disodium $\alpha$-naphthyl phosphate and $0.25 \%$ naphthanil diazoblue $\mathrm{B}$ in $0.2 \mathrm{M}$ acetate buffer at $\mathrm{pH} 4.0$ was poured on the surface of the agar-gel, which was held at $37^{\circ} \mathrm{C}$ for 2 hours.

\section{Enzyme assay in the genetic analysis}

The "slow" phosphomonoesterase group of the wild-type strain $R P$ and the "fast" group of the multichromosomal mutant strain ro; $\mathrm{ct} ; \mathrm{cm}$, were assayed to determine the linkage group of Phos-alleles which is responsible for the electrophoretic characteristics of acid phosphomonoesterases. Since recombination does not occur in male house flies, the $\mathrm{F}_{2}$ obtained from the backcross $\left\{r o ; c t ; c m\right.$ 우 $\times \mathrm{F}_{1}(r o ; c t ; c m$ 우 $\left.\times R P \hat{\rho}) \hat{\delta}\right\}$ were separated into their phenotypes and compared with each other for electrophoretic characteristics.

The 5 th-chromosome locus of Phos-allele was determined with the aid of the marker strain carrying alleles car ar on the 5 th chromosome, and with the wild $R P$ strain. The $\mathrm{F}_{1}$ female hybrids from cross ( $\operatorname{car} a r+\times R P \hat{\circ}$ ) were backcrossed to the parental mutant males in single pair cultures as follows:

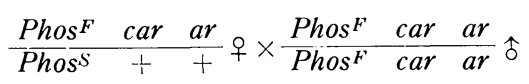

Then, the $F_{2}$ progeny flies of each phenotype obtained from the backcross were tested individually for the acid phosphomonoesterase bands. 


\section{RESULTS AND DISCUSSION}

\section{1. $p H$ and phosphomonoesterase activity relationships}

The influence of $\mathrm{pH}$ on the enzyme (phosphomonoesterase) in the house fly splitting naphthylphosphate (disodium salt) was investigated; acetate buffer $(0.2 \mathrm{M})$ was used for $\mathrm{pH} 2.6 \sim 5.4$, and tris buffer $(0.2 \mathrm{M})$, for $\mathrm{pH} 6.4 \sim 10.0$. The results are shown in Fig. 1 .

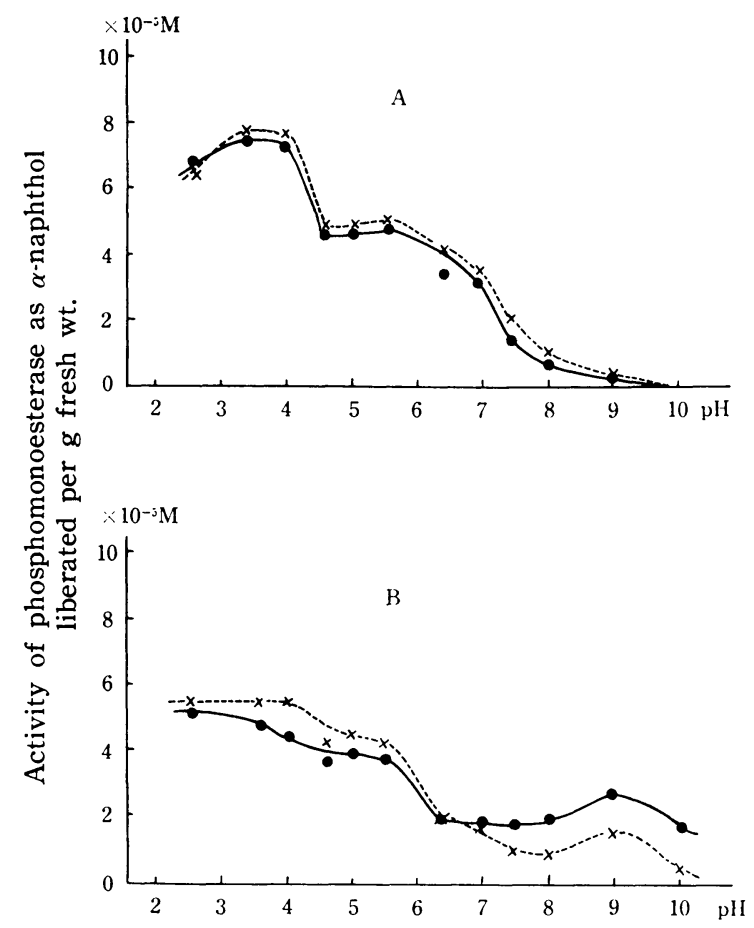

Fig. 1. Phosphomonoesterase activity of the house fly at various pH. Disodium $\alpha$-naphthylphosphate substrate was used.

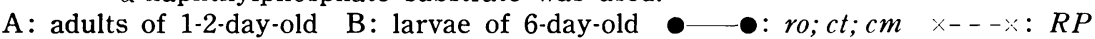

In adult flies, higher phosphomonoesterase activity was observed in acidic portion, and alkaline phosphomonoesterase was not found in either the diazinon-resistant $R P$ or the susceptible ro; $\mathrm{ct} ; \mathrm{cm}$ strains. Two components may exist in phosphomonoesterases of adult flies with respect to their optimum $\mathrm{pH}$, one being active in the range of $\mathrm{pH} 3 \sim$ 4 , and the other at $\mathrm{pH} 5 \sim 6$. This was confirmed moreover by the results of inhibition experiments summarized in Fig. 2. Sodium fluoride at $10^{-4} \mathrm{M}$ concentration inhibited the acid phosphomonoesterase at $\mathrm{pH} 3.0$ and 5.0, but not at $\mathrm{pH}$ 7.0. Zinc chloride at 10-3 $\mathrm{M}$ did not inhibit at $\mathrm{pH} 3.0$ and 5.0, but inhibited the activity at $\mathrm{pH} 7.0 . \mathrm{MgCl}_{2}$ had no effect on the activity at any $\mathrm{pH}$ range tested.

In the larvae (6-days after hatching) the $\mathrm{pH}$ and phosphomonoesterase activity 


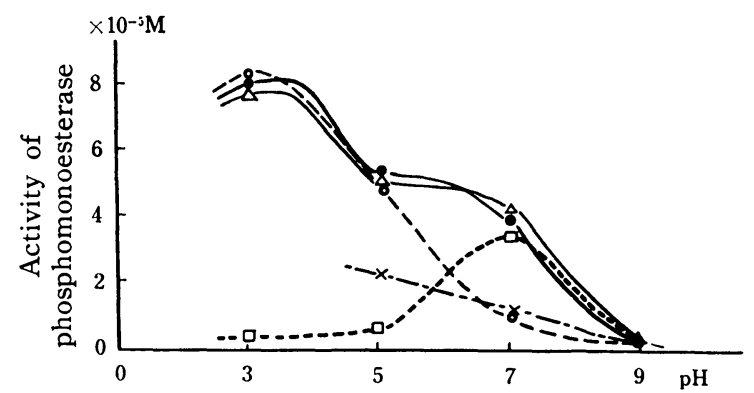

Fig. 2. Influence of various inhibitors or activators on phosphomonoesterase activity of the house fly ( $R P$ strain).

- - $\bullet$ : control $\square \cdot \cdots \cdot \square: 1 \times 10^{-4} \mathrm{M} \mathrm{NaF} \quad 0_{---0}: 1 \times 10^{-3} \mathrm{M} \mathrm{ZnCl}_{2}$

$x \cdot-\cdot-x: 1 \times 10^{-3} \mathrm{M} \mathrm{PO}_{4}^{--}$

$\triangle-\Delta: 1 \times 10^{-4} \mathrm{M} \mathrm{MgCl}_{2}$

relationship was somewhat different from adult flies. In addition to the higher phosphomonoesterase activity which was detected in acidic portion of larval extracts just as in adults, an alkaline phosphomonoesterase which was almost undetectable in adults exhibited in larvae a well-defined peak at $\mathrm{pH} 9.0$.

2. Changes of phosphomonoesterase activity in developmental stages of the house fies

Qualitative and quantitative changes in phosphomonoesterases were observed during

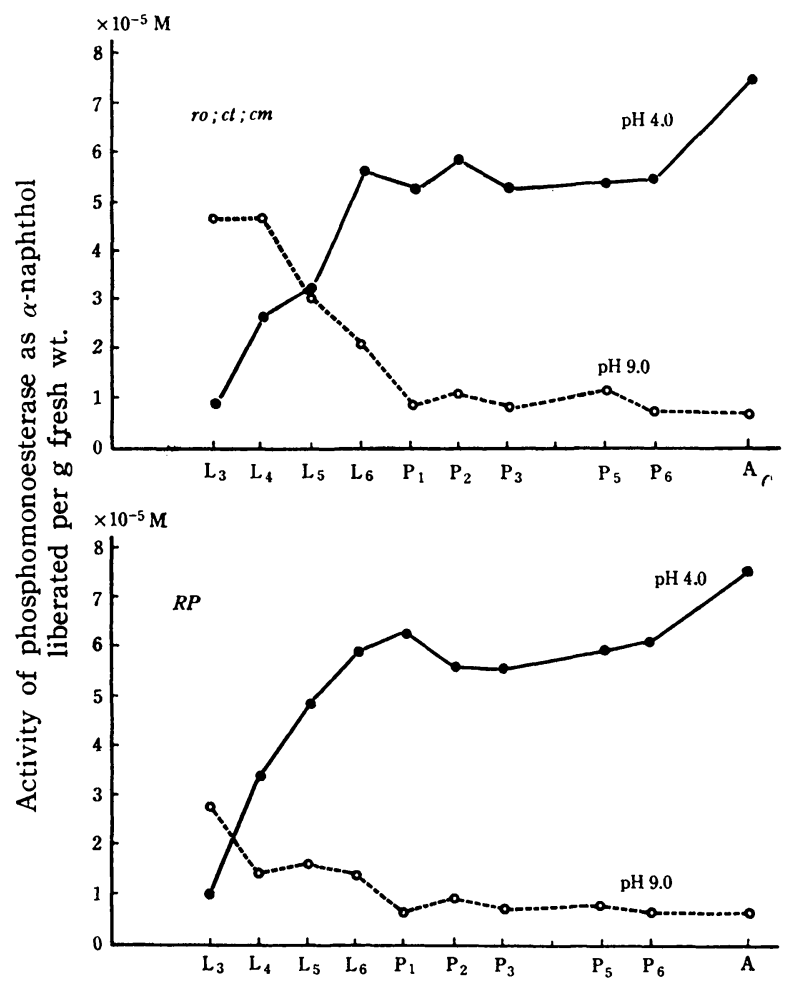

Fig. 3. Phosphomonoesterase activity in the homogenate of house flies of different ages. Disodium $\alpha$-naphthylphosphate substrate was used. 
the development of the house flies. Alteration in activity at different stages of development are shown in Fig. 3. The alkaline phosphomonoesterase activity with a peak at $\mathrm{pH} 9.0$ disappeared at the beginning of pupation, and maintained lower levels through out the pupal period and adult stage. On the other hand, the acid phosphomonoesterase activity measured at $\mathrm{pH} 4.0$ increased as the larval period proceeded, and these increased levels were maintained throughout the pupal period and adult stage. These results agree with those of Barker and Alexander (1956), who reported changes in acid and alkaline phosphatase activities during the life cycle of house flies in greater detail.

\section{Multiple forms of acid phosphomonoesterase}

The acid phosphomonoesterase of the house fly when tissue extracts of each strain are subjected to the thin-layer electrophoresis can be devided into fast and slow groups each containing several electrophoretically different molecular species (Figs. 4 and 5).

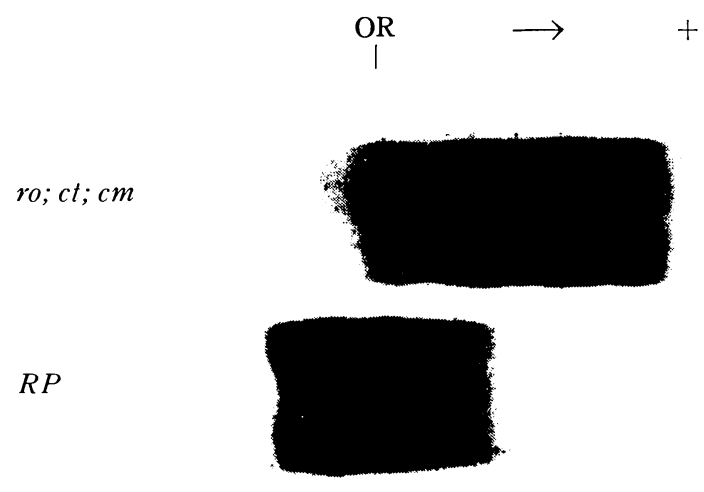

Fig. 4. Zymogram patterns of acid phosphomonoesterases in the house fly. OR shows the origin.

Two different electrophoretic variants between different laboratory stocks were observed, one is a group having fast-moving bands $(F)$, and the other a group of slow-moving bands $(S)$, and each consisted of about five bands.

The phenomenon suggested that the charge of the enzymatic protein of all the bands in the group is identically changed by a single mutation in the gene responsible for the enzymatic activity, and that the multiple molecular forms of this enzyme are the products of the same gene. However, the nature of the banding phenomenon is not yet entirely understood. As shown in Fig. 5, the electrophoretic differences were due to strain variations rather than to insecticide-resistance.

The similar phenomenon has been observed in another system. Native alkaline phosphatases of Escherichia coli have been found to behave as several electrophoretically different molecular species in starch-gel electrophoresis (Bach, Signer and Levinthal 1961), and single mutations in the alkaline phosphatase structural gene which change the 


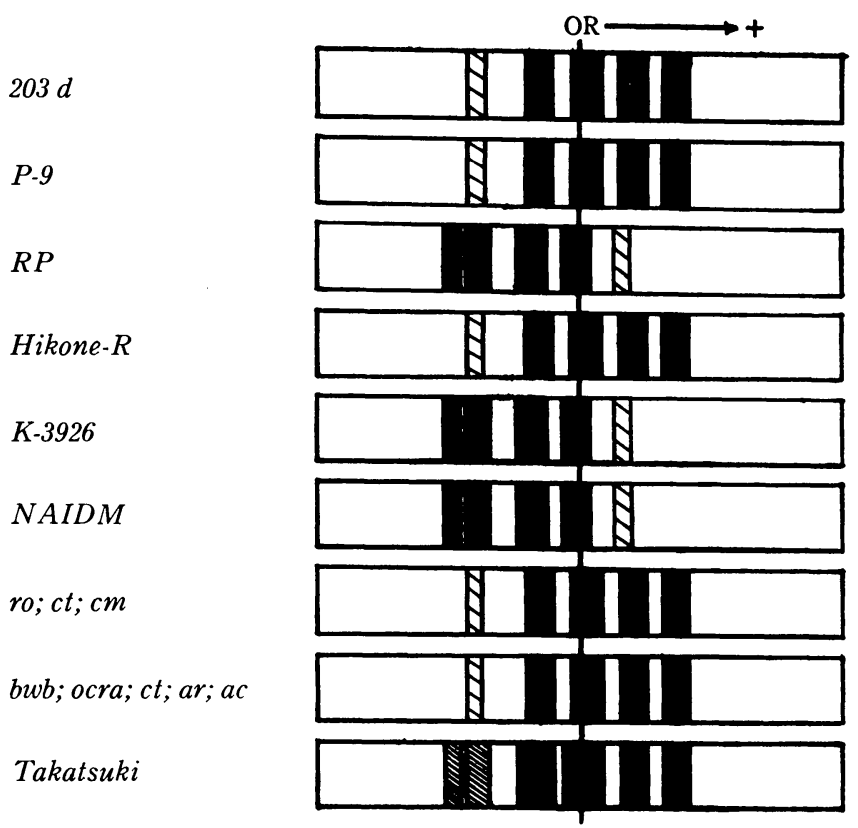

Fig. 5. Zymogram patterns of acid phosphomonoesterase for several strains of adult house flies. OR shows the origin.

charge or the enzymatic activity of the protein affested all the bands identically, indicating that they are all the product of the same gene. Hybrid enzymes which have intermediate electrophoretic mobility were formed in heterozygotes (Levinthal, Signer and Fetherolf 1961).

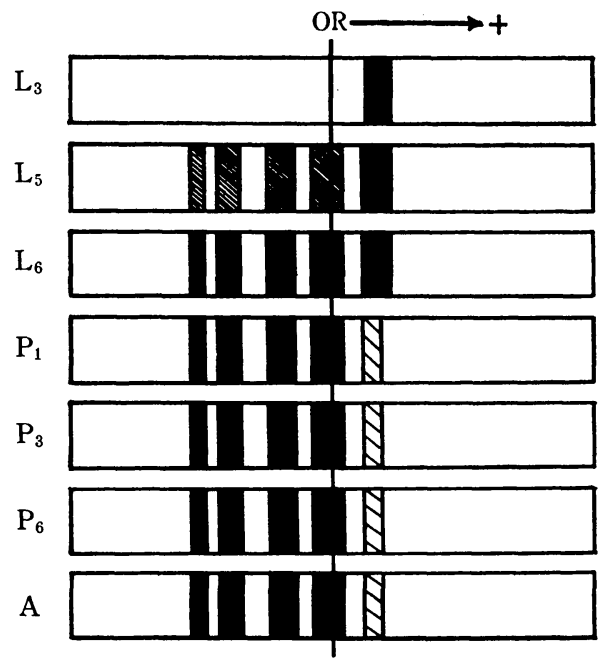

Fig. 6. Variations of zymogram patterns of acid phosphomonoesterase with the developmental stages of house flies ( $R P$ strain).

$\mathrm{L}_{3}$ : 3-day-old larvae, $\mathrm{L}_{5}$ : 5-day-old larvae, $\mathrm{L}_{6}$ : 6-day-old larvae, $\mathrm{P}_{1}$ : 1-day-old pupae,

$\mathrm{P}_{3}$ : 3-day old pupae, $\mathrm{P}_{6}$ : 6-day-old pupae, $\mathrm{A}$ : adults. 
Our results showed that in the house fly the heterozygous hybrids contained both groups of phosphomonoesterases of which the parents each had only one.

\section{Developmental and tissue specificities of zymograms}

The changes of the electrophoretic phosphomonoesterase patterns among the different developmental stages detected at $\mathrm{pH} 4.0$ are shown in Fig. 6. A positively-migrating faster band detected in 3 6 day-old-larvae disappeared at the critical stage of pupation. Five different acid phosphomonoesterase bands, except the above mentioned larval band, were detected in later larvae, pupae and adults. Their electrophoretic mobilities, numbers and relative intensity of the bands remained unchanged. Similar results were obtained from a strain of the house fly producing bands of the "fast" phosphomonoesterase group. These results parallel the changes in phosphomonoesterase activity during development already shown in Fig. 3.

In Fig. 7, the results recorded for the zymogram patterns of acid phosphomonoesterase in different tissues of the house flies are shown. Body fluid contains no detectable acid phosphomonoesterase, and the tissue extracts of the heads and guts gave same patterns as that of whole flies.

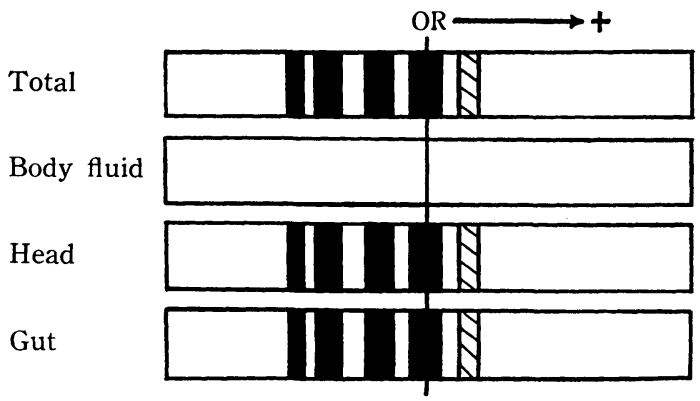

Fig. 7. Diagram showing zymogram patterns of acid phosphomonoesterases from different tissue extracts of house flies ( $R P$ strain).

From these results, 5 different acid phosphomonoesterase species in each band group were revealed to be always detected simultaneously from later larvae, pupae and adults, in stead of the detection of different bands specific for tissues or developmental stages except a band detected in larvae alone. This is similar to the alkaline phosphatase of E. coli, in respect that single mutations in the alkaline phosphatase gene or in growth conditions under which repressed the synthesis of enzymatic activity eliminated all the bands simultaneously, and never single basis or any special combinations of them (Bach et al. 1961).

\section{Genetic analysis of acid phosphomonoesterase}

The wild strain RP of "slow" phosphomonoesterase group, and multichromosomal mutant strain ro; $c t ; c m$ of "fast" phosphomonoesterase group, were used in order to 
determine the linkage group of the difference in electrophoretic mobility of phosphomonoesterase. Each strain was established to homozygous stock for the phosphomonoesterases by the single pair mating.

The heterozygous $F_{1}$ males of Phos $^{S} /$ Phos $^{F}$ type produced by the cross of ro;ct;cm females and $P h o s^{F}$ homozygotes of $R P$ males, which were also heterozygous for the visible markers, were backcrossed to ro; $\mathrm{ct} ; \mathrm{cm}$ females. The relation between the phenotypes and zymogram patterns of acid phosphomonoesterase in $\mathrm{F}_{2}$-progenies obtained from the backcross $\left\{r o ; c t ; c m\right.$ $\times \mathrm{F}_{1}(r o ; c t ; c m$ 우 $\left.\times R P \hat{\delta}) \hat{\delta}\right\}$ was examined electrophoretically. As shown in Fig. 8 , the zymogram patterns of each phenotypic $\mathrm{F}_{2}$-progeny

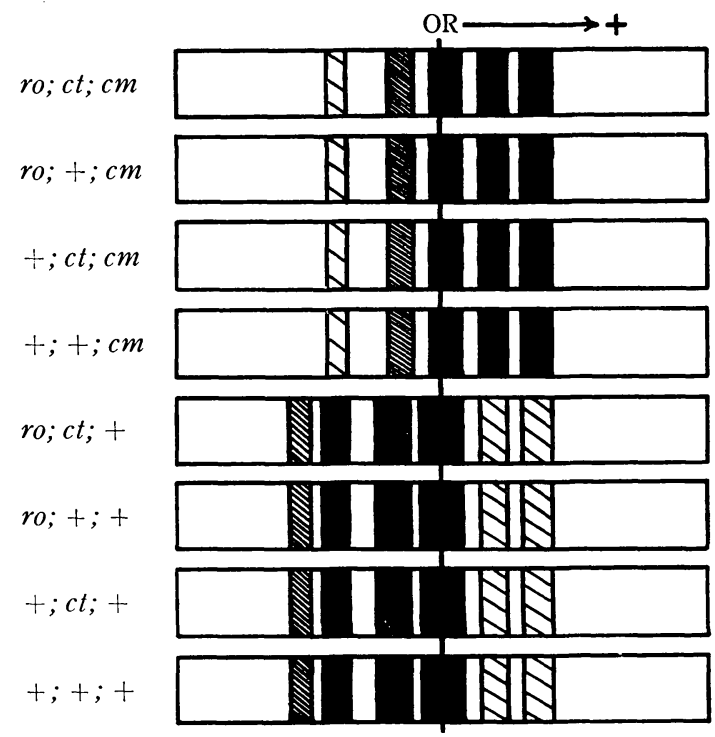

Fig. 8. Zymogram patterns of acid phosphomonoesterase for each phenotypic $\mathrm{F}_{2}$-progeny obtained from the backcross $\left\{\mathrm{ro} ; \mathrm{ct} ; \mathrm{cm}\right.$ 우 $\times F_{1}(\mathrm{ro} ; \mathrm{ct} ; \mathrm{cm}$ 우 $\times R P$ 全) $\hat{\delta}\}$.

obtained from the backcross showed a clear segregation; the zymogram patterns of ro; $c t ;+, r o ;+;+,+; c t ;+$, and $+;+;+$ (wild type) which had the 5 th chromosome carrying the factor of "slow" phosphomonoesterase derived from $R P$ in heterozygous condition, were slower in zymogram pattern than those of ro;ct;cm, ro; $+; \mathrm{cm},+; \mathrm{ct} ; \mathrm{cm}$. and $+;+; \mathrm{cm}$ progenies which had the 5th chromosome carrying the "fast" phosphomonoesterase derived from $r o ; c t ; c m$ in homozygous condition. Therefore, it is concluded that the gene or genes responsible for the difference of acid phosphomonoesterase in electrophoretic mobility are linked with the $\mathrm{cm}$ character, i. e., with the 5 th chromosome.

In order to establish the relationship between the loci of the phenotypic markers car, ar and the locus of Phos-allele, car ar females (this strain is belong to "fast" phosphomonoesterase group) were crossed to $R P$ males. $\mathrm{F}_{1}$-female progeny was backcrossed to car ar males, and $F_{2}$-progeny flies of each of the various phenotypes were tested for their acid phosphomonoesterase bands. Fig. 9 shows the typicals of $P h o s F / F$ 
1

2

3

4

5

6

7

8

9

10

11

12

Fig. 9. Zymogram patterns of acid phosphomonoesterase from the breis of individual flies. Numbers of 5, 8 and 11 show Phos $F / F$ types and the remainder the $F / S$ types. and $F / S$ types detected individually in the house flies. Total 564 flies were tested for their electrophoretic behaviors. From the results given in Table 1, rates of crossovers between Phos and car, Phos and $a r$, and $c a r$ and $a r$ were calculated to be $26.1,30.6$, and $5.8 \%$ respectively, according to the expression corrected for the viability of mutants as suggested by Hiroyoshi (1963).

Thus, the Phos locus on the 5 th chromosome became evident to be different from the locus responsible for diazinon-resistance which determined by Tsukamoto (1964), showing that the mechanism of diazinon-resistance is not related to the different electrophoretic mobility of acid phosphomonoesterase in the house fly. Alexander et al. (1958) studied the differences in the phosphatase activity of susceptible and DDT-resistant house flies and susceptible and chlordaneresistant cockroaches. And although significant differences were found in the acid and alkaline phosphatase activity between the sexes of both resistant and susceptible insects and also differences

in the acid phosphatase activity between females of one DDT-resistant and one susceptible strain of insects, it was concluded that these differences were due to strain variations rather than to resistance.

However, Menzel et al. (1963) suggested that the phosphatase activity of malation-resistant house flies is more numerous and more active than susceptible strain in the starch-gel electrophoresis. Our results, as shown above, suggested that at least acid phosphomonoesterase has no correlation to organophosphate resistance in the house fly. In further experiments concerning with this problem, esters which exist in insect body should be used as substrates, because though the naphthylphosphate ester has overlapping substrate specificity and is easily detectable substrate, its physiological function is not yet entirely understood. 
Table 1. Recombinations between $c a r$, $a r$ and Phos from the backcross

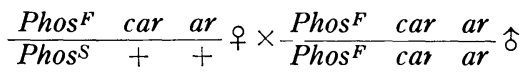

\begin{tabular}{|c|c|c|}
\hline Visible marker & Phosphomonoesterase & Number of flies \\
\hline car ar & $F / F$ & 182 \\
\hline car ar & $F / S$ & 71 \\
\hline car + & $F / F$ & 24 \\
\hline car ar & $F / S$ & 5 \\
\hline$+a r$ & $F / F$ & 1 \\
\hline car ar & $F / S$ & 8 \\
\hline \multirow{2}{*}{$\frac{+}{c a r} \frac{+}{\text { ar }}$} & $F / F$ & 70 \\
\hline & $F / S$ & 203 \\
\hline
\end{tabular}

Rates of recombination were culculated by the method suggested by Hiroyoshi (1963).

Recombination between $c a r$ and $a r=5.791 \%$

Recombination between ar and Phos $=30.634 \%$

Recombination between $c a r$ and Phos $=26.054 \%$

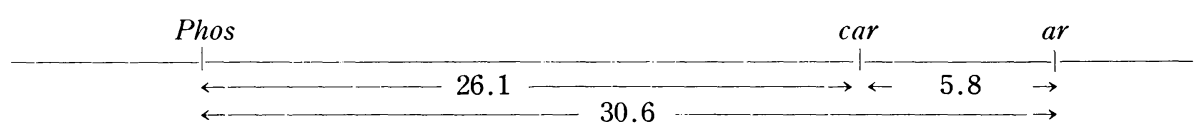

\section{SUMMARY}

Acid phosphomonoesterases of the house fly have been separated by the thin-layer el ectrophoretic technique of Ogita. A study of migratory behavior in the various stages of the life cycle showed that a positively migrating faster band is characteristic of larvae, while two different electrophoretic band groups were observed in adults, one a fast-moving band group $(F)$ which migrated toward the anodal side, and the other a slow-moving group $(S)$ which migrated toward the cathodal side each consisting of five electrophoretically different molecular species. The tissue specificity or the zymogram patterns of various stages in pupae and adults showed that these five molecular species revealed or eliminated simultaneously, and neither singly nor in any combinations. The inheritance of these electrophoretic variants is controlled by a pair of codominant alleles of Phos-locus which is $26.1 \pm$ map units apart from car-locus of the 5 th chromosome on which the genes responsible for esterases and diazinon resistance gene are located. The electrophoretic variants of acid phosphomonoesterase have been found to show no relation to insecticide-resistance.

\section{ACKNOWLEDGMENT}

The authors are indebted to Prof. H. Kikkawa for his invaluable advice and encouragement, and to Dr. A. W. A. Brown, University of Western Ontario, Canada, for his 
kind reading of the original manuscript. This investigation was supported by a grant given by WHO, and also by a PHS research grant (GM 10154) from the National Institute of Health, Public Health Service, U.S. A, and also by a Grant for Scientific Research from the Ministry of Education, Japan.

\section{LITERLATURE CITED}

Alexander, B.H., R. J. Barker, and F.H. Babers, 1958 The phosphatase activity of susceptible and resistant house flies and german cockroaches. J. Econ. Ent. 51: 211-213.

Asperen, K. van, and F. J. Oppenoorth, 1960 The interaction between organophosphorus insecticides and esterases in homogenates of organophosphate susceptible and resistant houseflies. Ent. Exptl. Appl. 3: 68-83.

Bach, M. L., E. R. Signer, C. Levinthal, and I. W. Sizer, 1961 The electrophoretic patterns of alkaline phosphatase from various E. coli mutant. Fed. Proc. 20: 255.

Barker, R. J., and B.H. Alexander, 1956 Acid and alkaline phosphatase in house flies of different ages. Ann. Ent. Soc. Amer. 51: 255-257.

Beckman, L., and F. M. Johnson, 1964 Variations in larval alkaline phosphatase controlled by $A p h$ alleles in Drosophila melanogaster. Genetics 49: 829-835.

Gahne, B., 1963 Genetic variation of phosphatase in cattle serum. Nature 199: 305-306.

Gomori, G., 1950 Human esterases. J. Lab. Clin. Med. 42: 445-453.

Hiroyoshi, T., 1963 Calculating method to correct differential viabilities in linkage tests and its application to linkage maps of the housefly. Japan. J. Genetics 38: 183.

Hopkinson, D. A., N. Spencer, and H. Harris, 1963 Red cell acid phosphatase variants: A new human polymorphism. Nature 199: 969-971.

Hopkinson, D. A., N. Spencer, and H. Harris, 1964 Genetical studies on human red cell acid phosphatase. Human Genetics 16: 141-154.

Levinthal, C., E. R. Signer, and K. Fetherolf, 1962 Reactivation and hybridization of reduced alkaline phosphatase. Proc. Natl. Acad. Sci. 48: 1230-1237.

Menzel, D. B., R. Craig, and W. M. Hoskins, 1963 Electrophoretic properties of esterases from susceptible and resistant strains of the housefly, Musca domestica L. J. Ins. Physiol. 9: 479-493.

Ogita, Z., 1962 Genetico-biochemical analysis on the enzyme activities in the house fly by agar gel electrophoresis. Japan. J. Genetics 37: 518-521.

Ogita, Z., 1963 a Enzyme separation by agar gel electrophoresis in D. melanogaster. Drosophila Information Service 37: 142.

Ogita, Z., $1963 \mathrm{~b}$ Separation and revelation of isozyme by means of the thin layer electrophoresis. Nucleus and Cytoplasm 5: 7-18. (in Japanese)

Ogita, Z., 1964 Improved agar gel media for thin layer electrophoresis. Med. J. Osaka Univ. 15: 141-153.

Ogita, Z., and T. Kasai, 1963 Genetico-biochemical analysis on the esterase activities in the house fly. Japan. J. Genetics 38: 200.

Ogita, Z., and T. Kasai, 1964 a Separation and revelation of specific esterase in thin layer electrophoresis by means of a pH-indicator method. SABCO J. 1: 37-41. (in Japanese)

Ogita, Z., and T. Kasai, $1964 \mathrm{~b}$ Biochemical differences between insecticide resistant and susceptible flies. Information circular on insecticide resistance (WHO). 46: 32-33.

Ogita, Z., and T. Kasai, 1965 a Genetic control of multiple esterases in Musca domestica. Japan. J. Genetics 40 : 1-14. 
Ogita, Z., and T. Kasai, $1965 \mathrm{~b}$ Genetico-biochemical analysis of specific esterases in Musca domestica. Japan. J. Genetics. 40: 173-184.

Oppenoorth, F.J., and K. van Asperen, 1960 Allelic genes in the housefly producing modified enzymes that cause organophosphate resistance. Science 132: 298-299.

Rendel, J., and C. Stormont, 1964 Variants of ovine alkaline serum phosphatases and their association with the R-O blood groups. Proc. Soc. Exptl. Biol. Med. 115: 853-856.

Tsukamoto, M., 1962 Genetic analyses of the housefly resistance to insecticides. Japan. J. Sanit. Zool. 13: 179-180. (Abstract in Japanese)

Yoshitake, N., and M. Akiyama, 1964 Genetical studies on the acidphosphatase in the blood of the silkworm, Bombyx mori L. Japan. J. Genetics 39: 26-30. 